\title{
What is Practical Knowledge?
}

\author{
Gustavo Guzman \\ Griffith University \\ Department of Management \\ Gold Coast campus \\ Queensland 4222 \\ Australia \\ PH: +617 55528919 \\ Fax: +617 55529206 \\ g.guzman@griffith.edu.au
}

Paper acepted for publication in The Journal of Knowledge Management 2009 forthcoming. 


\title{
What is Practical Knowledge?
}

\begin{abstract}
Purpose: This paper explains the key dimensions of practical knowledge. It is argued that practical knowledge and practice are two sides of the same phenomenon and possess objective and subjective dimensions.

Approach: The development of this paper involved an in-depth review of the workplace learning, cognitive education and practice-based management literatures supported by Giddens and Habermas’ insights on action.

Research Implications: The proposed framework complements practice-oriented management research. Whilst there is a significant body of literature dealing with workplace action-learning approaches, still it is not clear what approach to use in what situation. The proposed framework might assist in this task since it recognises different configurations of practice and their associated PK.
\end{abstract}

Originality: This paper integrates parallel literatures from different theoretical backgrounds in order to explain the main dimensions of practical knowledge.

Classification: Conceptual paper

Keywords: practical knowledge, practice, management, knowing, know-how

\section{INTRODUCTION}

The importance of practice has already been discussed by the philosophy

(Bourdieu, 1990), sociology (Giddens, 1982), economy (Dosi, Nelson and Winter, 2002) and management and organization (Leonard and Swap, 2004; Schatzki, 2005)

literatures. Practice is also a significant research issue in the cognitive education (e.g. 
Brown, Collins and Duguid, 1989; Lave and Wenger, 1991; Billett, 1994), health (Carper, 1978; Berragan, 1998) and anthropology (O’Connor, 2005) literatures. From the organization and management perspectives, significant advances have been made in the understanding of the organizational factors that either support (Argyris and Schon, 1974; Schon, 1983) or block (Pfeffer and Sutton, 2000) turning knowledge into action, the role of practice and experimentation in innovation (Dougherty, 2004; Leonard, 1998) and the crucial aspects of learning in the workplace (Eraut, 2000; Boud and Garrick, 2001; Kolb, 1984). Different approaches have focussed either on the cognitive, the learning aspects or the epistemology of knowledge dimension of practice. As a result of this diversity, different traditions and models have emerged.

This is positive, since heterogeneous views provide alternative explanations useful for theory building. This diversity, nevertheless, also hints at the scant agreement on the nature and role of the basic constituencies of practical knowledge (PK), one of the crucial aspects of a knowledge-based theory of the firm (Spender, 1993, 2005). There is fragmentation in this field of research since converging, overlapping and diverging practice-related concepts, such as practice (Chaiklin and Lave, 1993), action (Collins and Kush, 1998), knowledge-as-practice (Spender, 2005), knowing (Nicolini et al., 2003), habitus (Bourdieu, 1990) and activity (Blackler, Crump and McDonald, 2003), have emerged, creating further confusion. This paper fills this research gap by proposing a framework that outlines the main dimensions of PK and its interrelationships.

The proposed framework combines cognitive approaches of practice with socially constructed, situated and processual views of practice. Cook and Brown (1999) pointed out that the question of whether PK resides in the mind of the person or in 'practice' is a crucial component in studies of practice. Echoing Giddens' (1982) 
and Habermas’ (1984) insights, this study takes the view that PK has both cognitive and practical dimensions. That is, in contrast to research that approaches practice as residing in people’s minds (Anderson, 1983; Gourlay, 2004), either in action (Nyiri, 1988), experience (Tsoukas, 2005), practice (Bourdieu, 1990), or doing (Gherardi, 2000), this paper sees those approaches as complementary. On the one hand, for example, practice-based approaches expel the agent, individual knowledge and individual learning from practices and knowing (Brauner, Becker and Jordan (2005). On the other hand, cognitive views of knowledge not only emphasize the individual level at the cost of overlooking the organizational level, but also assert that cognition resides in the heads of people dismissing the processual, social, situated, contextdependent and material character of knowing (Marshall, 2007). The view that knowledge (rules, for example) necessarily needs interpretation to be applied, and therefore users are the ones who determine when and how to use rules (Collins, 1990), further supports the complementary character of cognitive (mental) and practical dimensions.

Before presenting the framework, it is necessary to clarify a set of terms whose meanings are contiguous and overlap to some extent, generating confusion in the literature. Orlikowski (2002) and Dougherty (2004), for example, used the terms 'practice' and 'activities' in such a way to convey the idea of putting theory (ideas/concepts) into action. Because practice, action and activity have different connotations, in this study, practice is preliminarily defined as a set of actions (human behaviour) undertaken by one or more persons in order to achieve an outcome, with or without the use of artefacts. That is, in this study, practice involves a set of planned or unplanned actions that can be common, habitual and frequent, or emergent, casual and unexpected. Action, in turn, is conceptualized as the intentional behavioural process 
encompassing a combination of physical movements in order to achieve a specific outcome. Finally, activity is defined as a synonym of action. Those terms have been defined in such a way to convey a meaning that is aligned with the focus of the study: PK used in order to perform actions with or without the mediation of artefacts.

In the next section, after reviewing the literature, the author conclude that PK has two dimensions, one explicit and one tacit. Subsequently components and relationships of the PK framework are detailed. In the conclusion, strengths and weaknesses of the proposed framework are discussed as well as potential research avenues.

\section{SO WHAT IS PRACTICAL KNOWLEDGE?}

While philosophical analyses of practice have focussed mainly on the 'production of action' (i.e. the concept of action itself, reasons, intentions and motives), sociologists have given significant consideration to the 'consequences of action', including institutions, conflict, power and social change. Philosophical and sociological analyses of practice, however, seem to have evolved in parallel without building one on the other (Giddens, 1982). In order to overcome this shortcoming, the PK framework is informed by both sociological and philosophical views of practice.

On the one hand, Giddens' (1982) structuration theory, by integrating production and consequences of action, contributes to understanding the idea of PK since it encompasses the macro-micro, agency-agent and knowing-practice dimensions. According to Giddens (1982), the world of social practice is simultaneously shaped by social structures (institutions, traditions and rules) on the one hand, and human agency on the other. That is, social actions and structures are both source and outcomes of each other that simultaneously enable and/or constrain 
their evolution. The idea of duality of structure is one of the bases of the proposed PK framework since it helps to examine the constitution of action. Social structures and social practices are reflected in the PK framework as objective and subjective dimensions that enable and constrain PK realization. This means that any theory of PK needs to consider not only the deliberate and conscious aspects of PK, but also both the unintended and the unacknowledged consequences of action. The latter, as Giddens (1982) notes, binds what he calls ‘the knowledgeability of human agents’ (p. 32). Furthermore, adhering to Giddens' duality of structure argument, the proposed PK framework takes an equilibrated (dual) view of the role of structure and action, that is, structure constraining actions and actions shaping structure simultaneously. Actions and structure, however, as Craib (1992) noted, are two sides of the same phenomenon: social actions.

On the other hand, Habermas' theory of communicative action is also relevant to contextualize the PK framework. Focussing on language as a medium to coordinate action, Habermas (1984) differentiated three types of action (Pusey, 1987). Instrumental action is defined as a non-social action oriented to success only via the technological control of impersonal problems. Strategic actions are social actions that include intentions, strategies and decisions, and occur between rational opponents with competing views oriented towards success. Finally, there is communicative action, which involves social actions oriented towards reaching understanding in cognitive (to establish and review interpersonal relationships), interactive (to represent states and events) and expressive (to manifest experience) terms (McCarthy, 1978). These different views of practice are selectively applied in the development of the PK framework. In the following paragraphs, after developing an initial idea of PK, a framework explaining the main dimensions of PK is presented. 


\section{Practical Knowledge: A First Approximation}

Adhering to Giddens’ (1982) and Habermas’ (1984) pluralistic and integrative ideas of practice, this paper takes an interpretive view of knowledge (Daft and Weick, 1984; Nicolini and Meznar, 1995). Under this view, knowledge is seen as a multidimensional concept that can be simultaneously personal, situated and socially constructed (Sole and Edmondson, 2002; Tsoukas, 2005; Orlikowski, 2002; Vince, Sutcliffe and Olivera, 2002; Wenger, 1998). Knowledge might have multiple meanings since space for diverse interpretations, ambiguity and conflict exists (Alvesson, 2004; Bapuji and Crossan, 2005; Daft and Weick, 1984; Nicolini, Gherardi and Yanow, 2003). Because knowledge is multidimensional, PK can be conceptualized in different ways. However, because practice and PK are two sides of the same phenomenon, it is necessary to conceptualize both ideas.

On the one hand, practice can be approached as an array of human activities that are "embodied, materially mediated arrays of human activity centrally organized around shared practical understanding” (Schatzki, 2001: 2). This means that practice is embodied, depends on shared skills, understandings and assumptions, and is usually mediated by non-human (e.g. artefacts) and natural objects. Practice, therefore, refers "not only to what one does, but also to how one thinks about what one and others do" (Raelin, 2005: 83). On the other hand, PK can be defined as the ability to put into effect previously acquired knowledge in specific circumstances. Knowing, according to Tsoukas (2000: 106), involves “someone drawing distinctions ... Knowing how to act within a domain of action is to make competent use of the distinctions constituting that domain”. Smith (1988: 2-3) has expressed an encompassing conceptualization of PK that integrates experience, meaning and context: 
[PK has] ... been formed by our previous experiences ... our sensory contents are a matter of holistic structures, experienced as being tied intrinsically to certain kinds of surrounding conditions and to certain characteristic presuppositions and outcomes. Such outcomes are, most importantly, regularly recurring, so that we have been able to build up through experience a repertoire of perceptual structures which we are able spontaneously to call in aid in relevant circumstances.

In order to develop a better understanding of PK, however, it is necessary to go beyond definitions and focus on its main features. PK is situated, since it focuses on ongoing actions developing in a specific context that can be temporal, emergent and social (Thompson and Walsham, 2004; Tsoukas, 2000). This explains why PK involves the application of regulation strategies to cope with unexpected situations. It may include breaking established rules and the creation of alternatives to solve problems on the spot in order to adapt a performing action to the specific local conditions (Guérin 2001; Nyiri, 1988). PK is personal, since it encompasses feelings, intuition and social identity (Handley, Sturdy, Fincham and Clark, 2006; Moch, 1990; Polanyi, 1958). PK is embodied since human motor activities, or behaviour, consciously deployed, are necessary to perform a specific action (Collins and Kush, 1998). Because of this, individuals might be unable to explain something that they are consciously aware of, or they might be unconsciously aware of something they know (Collins, 1990). PK is also relational, because it is mediated by human and technological artefacts, which, in turn, have heterogeneous logics of action and history (Nicolini et al., 2003). Finally, PK possesses semantic aspects, since multiple meanings can be attributed to specific practical actions (Weick, 1995; Tsoukas, 2005). 
The multidimensional nature of PK suggests that PK cannot be 'transferred' but is 'learned' during action (Revans, 1966). The multidimensional nature of PK is also congruent with the three central structures of practice proposed by Giddens (1982). Firstly, structures of signification allow people to communicate with each other; in understanding each other, people use their interpretative schemas that are built upon structures of signification. Secondly, structures of domination are related to the transformative capability of actions derived from the use of power; because the structural properties of social systems involve rules and resources, the idea of action is connected to that of power. Finally, structures of legitimation refers to the normative aspects of actions.

The above concept of PK implies social processes in which trust-building, identity-sharing and socialization processes to build trust, credibility and respect among members are key to supporting PK sharing (Sole and Edmondson, 2002; Orlikowski, 2002). The workplace learning literature has pointed out that (practical) expert knowledge can be gained either formally through expert guidance in everyday activities (Tennant, 2001; Billett, 2001), or informally through implicit learning when there is no intention to learn, unplanned or spontaneous learning - or deliberate learning (Eraut, 2000). In both cases, sharing PK in workplace environments involves negotiation, compromise and influencing (Billett, 1996).

From the wide spectrum of practice-based approaches, Nicolini et al. (2003) have derived four traditions: knowing as culture and aesthetic understanding that emphasizes “...the context specific collectively held meaning in practices” (p. 13); the community of practice approach; the knowing as activity systems approach, in which “...a variety of actions, with different histories and logics of actions” (p. 17) play a significant role in the crystallization of actions; finally, the sociology of translation 
approach that “...does not limit the focus to language, discourse or human interactions, granting instead equal citizenship to a range of disparate and heterogeneous elements (technologies, artifacts, symbols and places) as active players in the process of ordering” (p. 18). The latter two approaches see knowing as part of complex interrelations of people, artefacts, language, collaboration and control.

By pointing out important epistemological aspects of the nature of $\mathrm{PK}$ as well as the processes surrounding PK sharing, the literature has without doubt made an important advancement towards the understanding of PK. Nevertheless, there seems to be no agreement regarding the basic components that constitute the idea of PK. The aim of this study, therefore, is to advance a theoretical framework that outlines the main dimensions of PK.

\section{Dimensions of Practical Knowledge}

Building on well established concepts such as know-how, knowing, experiential learning, procedural knowledge and practice, in this section the dimensions of PK are detailed. On the one hand, PK has explicit and tacit dimensions. On the other hand, PK is constituted by both knowledge and practice (Handley et al., 2006; Brauner, Becker and Jordan, 2005; Baumard, 1999; Tsoukas, 2005) (see Figure 1). Two clarifications are necessary. First, dimensions of the PK taxonomy are in reality a continuum rather than clear-cut categories. Hence, it is unlikely to find 'pure forms' of PK; conversely, hybrid forms of PK seem to be more likely to be found in realworld situations. Second, the identification of the prevalent dimension of PK seems to be crucial, because different forms of PK have differentiated epistemology of knowledge and need to be treated accordingly. PK sharing mechanisms, for instance, will be different depending on the prevalent constitutive elements of PK. 


\section{INSERT FIGURE 1 ABOUT HERE}

The points of departure to discuss the knowledge dimension of PK are the concepts of 'procedural knowledge' (Cohen and Bacdayan, 1994) and 'knowing' (Nicolini et al., 2003). While procedural knowledge refers to 'knowledge of how things are done' (Cohen and Bacdayan, 1994: 554), and includes both cognitive and motor activities, knowing "is a form of social practice that involves knowledge in action situated in the historical, social and cultural contexts ... and [is] embodied in a variety of forms and media” (Nicolini et al., 2003: 3). In both cases, it is knowledge that can only be acquired through practical experience, and it has both explicit and tacit components (Brauner et al., 2005; Polanyi, 1983). In both cases, however, their assumptions regarding the nature of knowledge are very different. In the former case, procedural knowledge is cognitive, and in the latter, knowing is in practice. In order to make sense of those views, and following Giddens' (1982) duality of structure idea, in this study it is proposed that PK has both explicit and tacit dimensions.

The explicit component of procedural knowledge (quadrant 1) refers to what Ryle (1962) called ‘know-how’, Blackler (1995) ‘encoded knowledge’ and Giddens (1982) 'discursive consciousness'. That is, it is knowledge about how to do a practical action that, although not clear and detailed, still can be either verbalized or explained through signs or drawings, including the capability to provide rational accounts of actions. Explicit components of knowledge, therefore, are generally insufficient to guide or explain how to do actions. Styhre, Josephson and Knauseder (2006), for 
example, noted that in the construction industry, designers' written instructions such as layouts and technical specifications needed to be "translated into actual practices in situ” (p. 91) because construction projects differ widely and are highly contextual. That is, designers write down their instructions and protocols without knowing the actual and future constraints of the specific site. The important feature of explicit procedural knowledge is that, because it is explicit to some extent, it can be deliberately shared and applied, even imperfectly.

The tacit component of procedural knowledge (quadrant 2) is composed of concepts, ideas and experience that cannot be either objectivized or explained. This knowledge can be effortlessly, unconsciously and automatically applied in order to perform a specific action. Because the tacit component of procedural knowledge is also situated, it is not possible to develop models or frameworks in order to share it. This is what Giddens (1982) named 'practical consciousness' and Nicolini et al. (2003) 'knowing'. The literature has made important advances in the understanding of tacit procedural knowledge that accompanies practice. Scribner’s (1986) studies on practical thought, for example, pointed to the importance of the individual's ability to formulate the problem situation considering current environmental limitations as well as the individual's own practical skills to solve the same problem in different ways. Similarly, and building on Argyris and Schon’s (1974) notion of theory-in-use, Schon (1983) showed the different intellectual processes that managers experience when organizing problem-solving processes during action by experimenting and reframing situated problems in order to cope with uncertainty, change and uniqueness.

Similarly, Berragan (1998) explained that nursing environments make widespread use of experiential, interpersonal and intuitive knowing. Gourlay (2004) suggested that PK can be appropriately transmitted through non-verbal signing associated with 
novices observing expert's practicum. Stacey (1996) pointed to the importance of knowing how to clarify preferences and problem-solving alternatives, since messy, poorly defined situations constrain the determination of the core nature of the problem. Clarifying preferences, however, is a political process, since it requires consensus building activities, while developing problem-solving alternatives requires formulating the problem in different ways, knowing how to differentiate between structured and unstructured problem situations as well as using metaphors (McCaskey, 1988; Boland and Greenberg, 1988). Finally, Rolfe (1997) suggested that novices become experts when they are able to construct informal theories out of practice. The tacit component of knowledge required to perform practice, therefore, can only be learnt through what Revans (1966) called experiential learning (or practice), in which managers can make sense of new situations, developing a gestalt understanding of apparently unrelated situations.

Shifting to the practice dimension of PK, it is possible to note that 'practice' was defined by Argyris and Schon (1974) as the realization of a set of actions developed by a person that either can or cannot be executed together artefacts, materials and other people. Actions, according to Collins and Kush (1998), need not only intentional physical movements or behaviour in order to exist, but also need to make sense in the specific society in which they take place. Actions can also be either polymorphic or mimeomorphic. Polymorphic actions can be deployed in variegated forms and need an understanding of social life in order to make sense. That is, they need tacit knowledge in order to be performed and therefore cannot be mechanized. The act of 'greeting' is an example of a polymorphic action. Conversely, mimeomorphic actions can be performed in a narrow variety of ways and do not need an understanding of social life. Therefore, they do not need tacit knowledge and can be formalized, 
codified and mechanized. Punching a number in a telephone keypad is as example of a mimeomorphic action (Ribeiro and Collins, 2007). Independently of whether actions are polymorphic or mimeomorphic, action has transformative power since it can direct change in order to achieve specific outcomes; action also has a normative and communicative dimension since it is guided by rules; and, because of people's reflexive skills, actions can always be ‘done otherwise’ (Craib, 1992).

Practice, according to Eraut (2000), has explicit and tacit dimensions. Practice is explicit (quadrant 3) when an individual deliberately applies explicit procedural knowledge and is able to explain how the action is done - at least partially. Explicit practice is constituted mainly by mimeomorphic actions that for the most part need conscious, reason-dominated explicit procedural knowledge. Practice in this quadrant, therefore, can be established by logical rules and is goal-oriented (Spender, 2005). Because of those features, explicit practice can either be codified, such as in the case of a recipe to cook rice, or can be crystallized in a physical procedure, such as the mechanisms developed when using the Japanese Poka-Yoke technique in industrial environments (Evans and Lindsay, 2002). Explicit practice, therefore, is close to what Habermas (1984) called 'instrumental action'.

Practice is tacit (quadrant 4) when tacit knowledge based on previous experience is used - consciously or unconsciously - to perform emerging and intentional actions, and the individual performing them is totally unable to explain how she/he does a specific action (Eraut, 2000). There are two categories of tacit practice. The first category is constituted mainly by polymorphic actions that need tacit social understanding of the specific situation in order to be performed. Practice in this category is mostly intuitive and explorative, and deals, on an on-going basis, with the consequences of previous actions. That is, it helps to test hypotheses and generate 
meaning from both outcomes and processes (Spender, 2005). The second category is constituted by actions that are consciously never performed; that is, non-actions that are deliberately or intuitively deployed in order to achieve a specific outcome are an important part of practice since, if executed, they can alter outcomes. This implies that the individual performing the action has not only a social understanding of the specific situation, but also accumulated experience.

Taking the four quadrants together, it is possible to have an idea of the key dimensions of PK, and more importantly, this framework aids in better understanding the dynamics of PK. In some instances, the explicit dimension of PK (quadrants 1 and 3) might overcome the tacit dimension of practice, such as in the case of a recipe for cooking rice; while the individuals involved in the task perhaps have some experience with kitchen-related tasks, to cook rice they need a recipe. In other cases, the tacit dimension of PK (quadrants 2 and 4) can prevail over the explicit dimension, such as in the case of an experienced chess player engaging successfully in a simultaneous game. While he has significant experience, he has no advance knowledge of his adversaries' moves and is unable to explain how he wins the game. Similarly, the knowledge dimension of PK (quadrants 1 and 2) can overwhelm its practice dimension. Going to the cinema is an example of implementing previously planned actions, where the people involved know in advance what they will do and how they will do it. Finally, the practice dimension of PK (quadrants 3 and 4) might override its knowledge dimension, as in the case of the experienced surfer who is able to achieve a high performance in unknown seas without 'thinking' how to do it.

Before further explaining the idea of PK in the following section, it must be noted that the literature, following Wittgenstein, has agreed on the idea that it is not possible to fully articulate and codify PK, because “...rules [do] not contain the rules of their 
own application” (Collins, 1990: 30). Disagreements in the literature relate to the hierarchy of PK dimensions. Schatzki (2001) noted that while some observers maintain that the practice dimension rules over the knowledge dimension (e.g. Bourdieu, 1990; Spender, 2005), others argued for the combination of practical skills and perception, propositional knowledge, reasons and goals (e.g. Barnes, 2001; Giddens, 1982).

In this paper a dynamic perspective of dimension of PK is taken. This means that, rather than attempting to uncover which dimension is more important, the crucial aspect is to recognize the dynamic character, and therefore the fluid nature, of practice and PK, something that requires an evolving configuration of practice. In this sense the proposed PK framework might help both academics and practitioners to uncover the specific form and composition of PK.

\section{Practical Knowledge: A Second Approximation}

Considering the above taxonomy, PK can be defined as the blend of explicit and tacit procedural knowledge with explicit and tacit practice. This means that it is possible to differentiate two forms of PK. Explicit PK refers to the deliberate use of explicit procedural knowledge (encoded and embrained know-how) in order to perform mimeomorphic actions. For example, well-known and codified 'recipes' can be utilized to perform specific actions, such as cooking rice. Explicit PK, then, is related to the objective dimension in which artefacts, materials, people’s behaviour and performance are all well known to the person doing the action. This is why explicit PK can be planned and outcomes can be predicted to some extent.

Tacit PK, on the other hand, unconsciously and automatically applies tacit procedural knowledge (knowing) in order to perform polymorphic actions. Tacit PK 
is related to the subjective dimension, in which artefacts have different (some unknown) applications, and people’s performance and contextual situation are highly unstable. Thus, outcomes are uncertain and procedures cannot be planned. Because it is constituted by tacit and situated knowledge as well as being embodied to a significant extent, it is not possible to represent it by any exact theory (Polanyi, 1983). That is why it is not possible to explain how some actions, such as riding boards or fine-tuning pianos, are performed. Tacit PK, therefore, can only be embodied in the individual's mind (conceptual and cognitive skills) and in polymorphic actions involving a variety of motor, kinetic and sensorial abilities. Using Blackler's (1995) nomenclature, the tacit knowledge component of PK is embodied. As part of the tacit dimension of PK can be included the informal routines that individuals need to develop and use over time in order to cope with the expected performance of artefacts, materials and behaviour of individuals. Tacit PK, therefore, can only be acquired and performed through practice. Action-learning (Zuber-Skerritt, 2002) and experiencebased (Garrick, 2001) programs such as learning-by-doing, learning-by-trying and learning-by-failing are all part of the conceptualization-experimentation-reflection cycle (Kolb, 1984) that facilitates learning tacit PK.

The main difference between explicit and tacit PK is, on the one hand, the extent to which one is more situated, embodied and unstable than the other. On the other hand, explicit PK usually entails the performance of mimeomorphic actions, while tacit PK involves the performance of polymorphic actions. Thus, the idea of PK is close to the idea of procedural knowledge (Cohen and Bacdayan, 1994) and knowing (Nicolini et al., 2003), but PK differentiates the type of cognitive activity performed (tacit versus explicit) as well as the type of action (mimeomorphic versus polymorphic) performed when 'doing' practical activities. This concept of PK also 
goes beyond Scribner's (1986) practical thought ideas, since he emphasizes more the knowledge (i.e. the tacit components of procedural knowledge) than the practice dimension, leaving a gap in the relationships between actual practice and 'practical thought'.

\section{CONCLUSION}

This paper has outlined the constituent dimensions of PK. After discussing the epistemology of PK, a four-quadrant matrix was depicted detailing their main dimensions. It has been argued that PK is constituted by a knowledge dimension and a practice dimension, each of which can, in turn, have explicit and tacit features. This paper has taken a dynamic perspective suggesting an ever-evolving composition of practice and $\mathrm{PK}$, in which explicit and tacit procedural knowledge, together with explicit and tacit practice, acquire different configurations depending on embodied capacities, such as skills, tacit understandings, dispositions and the specific spacetime and resource limitations.

The PK framework brings implications for management practice, since recognizing the different configurations PK might adopt can assist in selecting the requisite mechanism for sharing/learning PK. That is, the PK framework complements latest practice-oriented management research. Leonard and Swap’s (2004) ‘deep smarts’ idea, for example, rediscovered the usefulness of action-learning approaches to promote 'transfer' of what the author has defined as PK. That is, they argue that, in order to transfer judgment and knowledge of experienced people, it is necessary to use active learning strategies, such as guided observation problemsolving and experimentation. Whilst there is a significant body of literature dealing with workplace action-learning approaches (Boud and Garrick, 2001), still it is not 
clear what approach to use in what situation. The proposed framework might assist in this task since it recognizes different configurations of practice and its associated PK. The case of negotiating a merger in a highly uncertain context, for example, represents $\mathrm{PK}$ in which the tacit dimension is the strongest one. There are high levels of uncertainty about how the future partners will behave and it is not possible to predict how to cope with uncertainty. While the experienced person might be unable to explain how it is done, she might successfully cope with her tasks because of her experience. Learning-by-doing, learning-by-experimenting and learning-by-failing techniques for sharing this form of PK can be adequate for this situation because polymorphic actions call for tacit PK, where the situation can only be dealt with during actual action. Conversely, in the case of implementing a well known management model, such as six-sigma, in a stable and well known context, the explicit dimension of PK prevails over its tacit dimension. This, in turn, means that, because actions are likely to be mimeomorphic and accumulated knowledge can be articulated and codified to some extent, PK can be shared through a combination of guidelines and guided-observation techniques.

Similarly, Orlikowski's (2002) study of practices pointed out a series of practices that a software company implemented in order to facilitate software development in a dispersed environment. The PK framework can be applied in order to establish the actual configuration of PK (that is, either explicit-oriented or tacit oriented) in order to set up an adequate mechanism to facilitate learning or knowledge sharing. The PK framework can also enhance the understanding of the idea of communities of practice (Wenger, McDermott and Snyder, 2002), since practice in this approach is equated with knowledge (“... practice is the specific knowledge the 
community develops, shares and maintains”, p. 29), leaving a gap in the role, features and nature of practice.

Limitations of the PK framework are related to the fact that, while offering a refined understanding of the nature of PK, it still does not explain what the constitutive elements of practice are and how they are interrelated. Consequently, it is necessary to further develop the idea of practice by detailing its main triggers (DeMartini and Whitbeck, 1987), components, boundaries, key agents as well as their interrelationships. Additionally, there is need for further studies in order to integrate the PK framework with ideas of uncertainty, equivocality and ambiguity (cf. Weick and Sutcliffe, 2001; Zack, 1998). Another research avenue awaiting further development is related to the exploration of relations between power and PK. As Giddens (1982) suggested, practice can have a ‘domination structure’ and this means that the way the different components of PK are configured can favour the political use of actions and PK.

\section{REFERENCES}

Alvesson, M. (2004), Knowledge Work and Knowledge-Intensive Firms, Oxford University Press, New York.

Anderson, J. R. (1983), The Architecture of Cognition, Harvard University Press, Cambridge, MA.

Argyris, C. and Schon, D. (1974), Theory in Practice, Jossey-Bass, San Francisco, CA. 
Bapuji, H. and Crossan, M. (2005), “External knowledge management strategies and firm performance”, in Gherardi, S. and Nicolini, D. (Eds.), The Passion for Learning, Univ. of Trento, Trento, Italy, 1, pp. 522-540.

Barnes, B. (2001). “Practice as collective action”, in Schatzki, T.R., Knorr Ceytina, K. and Savigny, E. (Eds.) The Practice Turn in Contemporary Theory, Routledge, London.

Baumard, P. (1999), Tacit Knowledge in Organizations, Sage, London.

Berragan, L. (1998), “Nursing practice draws upon several different ways of knowing”, Journal of Clinical Nursing, Vol. 7, pp. 209-217.

Billett, S. (1994), “Situated learning - a workplace experience”, Australian Journal of Adult and Community Education, Vol. 34 No. 2, pp. 112-130.

Billett, S. (1996), “Situated learning: bridging sociocultural and cognitive theorising”, Learning and Instruction, Vol. 6, pp. 263-280.

Billett, S. (2001), “Guided learning at work”, in Boud, D. and Garrick, J. (Eds.), Understanding Learning at Work, Routledge, London, pp. 151-64.

Billett, S. (2004), “Workplace participatory practices”, The Journal of Workplace Learning, Vol. 16 No. 6, pp. 312-324.

Blackler, F. (1995), “Knowledge, knowledge work and organizations: an overview and interpretation”, Organization Science, Vol. 16 No. 6, pp. 1021-46.

Blackler, F., Crump, N. and McDonald, S. (2003), “Organizing processes in complex activity networks”, in Nicolini, D., Gherardi, S. and Yanow, D. (Eds.), Knowing in Organizations, M.E. Sharpe, Armonk, NY, pp. 127-49.

Boland, R. and Greenberg, R. (1988), “Metaphorical structuring of organizational ambiguity”, in Pondy, L.R., Boland, R.J. and Thomas, H. (Eds.), Managing Ambiguity and Change, John Wiley \& Sons, Chichester, pp. 17-36. 
Boud, D. and Garrick, J. (2001), Understanding Learning at Work, Routledge, London.

Bourdieu, P. (1990), The Logic of Practice, Polity Press, Cambridge.

Brauner, E. Becker, A. and Jordan, S. (2005), “Organizational learning: the interplay of routinization and crisis in practices”, in Gherardi, S. and Nicolini, D. (Eds.), The Passion for Learning and Knowledge, Vol. I. University of Trento, Trento, pp. 13354.

Brown, J., Collins, A. and Duguid, P. (1989), "Situated learning and the culture of learning”, Educational Researcher, Vol. 18 No. 1, pp. 32-34.

Brown, J. and Duguid, P. (1991), “Organizational learning and communities-ofpractice”, Organization Science, Vol. 2 No. 1, pp. 40-57.

Carper, B. (1978), “Fundamental patterns of knowing in nursing”, Advances in Nursing Science, Vol. 1 No. 1, pp. 13-23.

Chaiklin, S. and Lave, J. (1993), Understanding Practice - Perspectives on Activity and Context, Cambridge University Press, Cambridge, MA.

Cohen, M.D. and Bacdayan, P. (1994), “Organizational routines are stored as procedural memory”, Organization Science, Vol. 5 No. 4, pp. 554-569.

Collins, H. (1990), Artificial Experts: Social Knowledge and Intelligent Machines, MIT Press, Cambridge, MA.

Collins, H. and Kush, M. (1998), The Shape of Actions: What Humans and Machines Can Do, MIT Press, Cambridge, MA.

Cook, S. and Brown, J. (1999), “Bridging epistemologies: the generative dance between organizational knowledge and organizational knowing”, Organization Science, Vol. 10 No. 4, pp. 381-400.

Craib, I. (1992), Anthony Giddens, Routledge, London. 
Daft, R., K. Weick. (1984), “Towards a model of organizations as interpretation systems”, Academy of Management Review, Vol. 9, pp. 284-95.

DeMartini, J.R. and Whitbeck, L.B. (1987), “Sources of knowledge for practice”, The Journal of Applied Behavioral Sciences, Vol. 23 No. 2, pp. 219-231.

Dosi, G., Nelson, R.R. and Winter, S. (2002), The Nature and Dynamics of Organizational Capabilities, Oxford University Press, Oxford.

Dougherty, D. (2004), “Organizing practices in services: capturing practice-based knowledge for innovation”, Strategic Organization, Vol. 2 No. 1, pp. 35-64.

Eraut, M. (2000), “Non-formal learning and tacit knowledge in professional work”, British Journal of Psychology, Vol. 70, pp. 113-136.

Evans, J.R. and Lindsay, W.M. (2002), The Management and Control of Quality, SouthWest Press, Cincinnati, Ohio.

Garrick, J. (2001), “The dominant discourses of learning at work”, in Boud, D. and Garrick, J. (Eds.), Understanding Learning at Work, Routledge, London, pp. 216-31. Gherardi, S. (2000), "Practice-based theorizing on knowing and learning in organizations”, Organization, Vol. 7, pp. 211-223.

Giddens A. (1982), Profiles and Critiques in Social Theory, Macmillan, London. Gourlay, S. (2004), “Knowing as semiosis: steps towards a reconceptualization of tacit knowledge”, in Tsoukas, H. and Mylonopoulos, N. (Eds.), Organizations as Knowledge Systems, Palgrave, Basingstoke, pp. 86-101.

Guérin, F. (2001), Compreender o Trabalho para Transformá-lo, Edgard Blücher, São Paulo.

Guzman, G. and Wilson J. (2005), “The soft dimension of organizational knowledge transfer”, Journal of Knowledge Management, Vol. 9 No. 2, pp. 59-74. 
Habermas, J. (1984), The Theory of Communicative Action, Vol. 1, Reasons and the Rationalisation of Society, Beacon Press, Boston.

Handley, K., Sturdy, A., Fincham, R. and Clark, T. (2006), “Within and beyond communities of practice: making sense of learning through participation, identity and practice”, Journal of Management Studies, Vol. 43 No. 3, pp. 641-653.

Kolb, D. (1984), Experiential Learning, Jossey-Bass, San Francisco, CA.

Lave, J. (1993), “The practice of learning”, in Chaiklin, S. and Lave, J. (Eds.), Understanding Practice - Perspectives on Activity and Context, Cambridge University Press, Cambridge, pp. 3-32.

Lave, J. and Wenger, E. (1991), Situated Learning - Legitimate Peripheral Participation, Cambridge University Press, Cambridge, MA.

Leonard, D. (1998), Wellsprings of Knowledge, Harvard Business School Press, Boston.

Leonard, D. and Swap, W. (2004), Deep Smarts: How to Cultivate and Transfer Business Wisdom, Harvard Business School Press, Boston, MA.

Marshall, N. (2007), “Cognitive and practice-based theories of organisational knowing and learning: incompatible or complementary?”, in Organization Learning, Knowledge and Capabilities Conference 2007, Richard Ivey School of Business, The University of Western Ontario, London, Ontario, 14-17 June 2007.

McCarthy, T. (1978), The Critical Theory of Jurgens Habermas, Polity Press, Cambridge.

McCaskey, M.B. (1988), “The challenge of managing ambiguity and change”, in Pondy, L.R., Boland, R.J. and Thomas, H. (Eds.), Managing Ambiguity and Change, John Wiley \& Sons, Chichester, pp. 1-15. 
Moch, S. (1990), “Personal knowing: evolving research and practice”, Scholarly Inquiry for Nursing Practice, Vol. 4 No. 2, pp. 155-165.

Nicolini, D., Gherardi, S. and Yanow, D. (2003), “Introduction: toward a practicebased view of knowing and learning in organizations”, in Nicolini, D., Gherardi, S. and Yanow, D. (Eds.), Knowing in Organizations, M.E. Sharpe, Armonk, NY, pp. 331.

Nicolini, D. and Meznar, M.B. (1995), “The social construction of organizational learning: conceptual and practical issues in the field”, Human Relations, Vol. 48 No. 7, pp. 727-746.

Nyiri, J.C. (1988), “Tradition and practical knowledge”, in Nyiri, J.C. and Smith, B. (Eds.), Practical Knowledge: Outlines of a Theory of Traditions and Skills, Croom Helm, Kent, pp. 17-52.

O’Connor, E. (2005), “Embodied knowledge - the experience of meaning and the struggle towards proficiency in glassblowing”, Ethnography, Vol. 6 No. 2, pp. 183204.

Orlikowski, W. (2002), “Knowing in practice: enacting a collective capability in distributed organizing”, Organization Science, Vol. 13 No. 3, pp. 249-273.

Pfeffer, J. and Sutton, R. (2000), The Knowing-Doing Gap, Harvard University Press, Boston.

Polanyi, M. (1958), Personal Knowledge. Towards a Post-Critical Philosophy, Routledge and Kegan Paul, London.

Polanyi, M. (1983), The Tacit Dimension, Peter Smith, Gloucester, MA.

Pusey, M. (1987), Jurgens Habermas, Tavistock Publications, London.

Raelin, J. (2005), “The role of facilitation in praxis”, Organizational Dynamics, Vol. 35 No. 1, pp. 83-95. 
Revans, R.W. (1966), The Theory of Practice in Management, Macdonald, London.

Ribeiro, R. and Collins, H. (2007), “The bread-making machine: tacit knowledge and two types of action”, Organization Studies, (forthcoming).

Rolfe, G. (1997), “Beyond expertise: theory, practice and the reflective practitioner”, Journal of Clinical Nursing, Vol. 6, pp. 93-97.

Ryle, G. (1962), The Concept of Mind, Barnes \& Noble, New York.

Schatzki, T. (2001), “Introduction: practice theory”, in Schatzki, T.R., Knorr Ceytina, K. and Savigny, E. (Eds.), The Practice Turn in Contemporary Theory, Routledge, London.

Schatzki, T. (2005), “The sites of organizations”, Organization Studies, Vol. 26 No. 3, pp. 465-484.

Schon, D.A. (1983), The Reflective Practitioner, Temple Smith, London.

Scribner, S. (1986), “Thinking in action: some characteristics of practical thought”, in Sternberg, R. and Wagner, R. (Eds.), Practical Intelligence: Nature and Origins of Competence, Cambridge University Press, Cambridge, pp. 112-25.

Smith, B. (1988), “Knowing how vs. knowing that”, in Nyiri, J.C. and Smith, B. (Eds.), Practical Knowledge: Outlines of a Theory of Traditions and Skills, Croom Helm, Kent, pp. 1-16.

Sole, D. and Edmondson, A. (2002), "Situated knowledge and learning in dispersed teams”, British Journal of Management, Vol. 13, pp. 17-34.

Spender, J. C. (1993), “Competitive advantage from tacit knowledge?”, Academy of Management, Best Paper Proceedings, pp. 37-41.

Spender, J.C. (2005), “An overview: what’s new and important about knowledge management? Building new bridges between managers and academics”, in Little, S. and Ray, T. (Eds.), Managing Knowledge: An Essential Reader, Sage, London. 
Stacey, R.D. (1996), Strategic Management and Organisational Dynamics, Pitman, London.

Styhre, A., Josephson, P. and Knauseder, I. (2006), “Organization learning in nonwriting communities”, Management Learning, Vol. 37 No. 1, pp. 83-100.

Tennant, M. (2001), “Is learning transferable?”, in Boud, D. and Garrick, J. (Eds.), Understanding Learning at Work, Routledge, London, pp. 165-179.

Thompson, M. and Walsham, G. (2004), “Placing knowledge management in context”, Journal of Management Studies, Vol. 41 No. 5, pp. 725-747.

Tsoukas, H. (2000), “Knowledge as action, organization as theory: reflections on organizational knowledge”, Emergence, Vol. 2 No. 4, pp. 104-112.

Tsoukas, H. (2005), “Do we really understand tacit knowledge?”, in Easterby-Smith, M. and Lyles, M. (Eds.), The Blackwell Handbook of Organizational Learning and Knowledge Management, Blackwell Publishing, Cornwall, pp. 410-27.

Vince, R., Sutcliffe, K. and Olivera, F. (2002), “Organizational learning: new directions”, British Journal of Management, Vol. 13, S1-S6.

Weick, K. (1995), Sensemaking in Organizations, Sage, Thousand Oaks, CA. Weick, K. and Sutcliffe, K. (2001), Managing the Unexpected, Jossey-Bass, San Francisco.

Wenger, E. (1998), Communities of Practice, Cambridge University Press, Cambridge, MA.

Wenger, E., McDermott, R. and Snyder, W. (2002), Cultivating Communities of Practice, Harvard Business School Press, Boston.

Zack, M. (1998), “If managing knowledge is the solution, then what is the problem?”, in Malhotra, Y. (Ed.), Knowledge Management and Business Model Innovation, Idea Group Publishing, Hershey, PA. 
Zuber-Skerritt, O. (2002), “The concept of action learning”, The Learning Organization, Vol. 9 No. 3, pp. 114-124.

Figure 1: A Taxonomy of Practical Knowledge

\begin{tabular}{|c|c|c|}
\hline \multirow[b]{2}{*}{$\begin{array}{l}\text { Procedural } \\
\text { Knowledge }\end{array}$} & Explicit & Tacit \\
\hline & $\begin{array}{c}\text { Know-How } \\
\mathbf{1}\end{array}$ & $\begin{array}{l}\text { Knowing } \\
2\end{array}$ \\
\hline Practice & $\begin{array}{l}\text { Explicjt } \\
\text { Practide }\end{array}$ & \begin{tabular}{l|l}
$\mathbf{4}$ \\
Tacit \\
Pradtice
\end{tabular} \\
\hline & $\begin{array}{c}\downarrow \\
\text { Explicit PK }\end{array}$ & Tacit PK \\
\hline
\end{tabular}

Source: Designed for this study 